\title{
Does Reading Correlate with Students' Critical Thinking? A Bridge to Literacy Practices
}

\author{
Sahiruddin Sahiruddin ${ }^{1,}$ Esti Junining ${ }^{1, *}$ M. F. Ubaidillah ${ }^{2,}$ Mei C. Len ${ }^{3}$ \\ ${ }^{l}$ Department of English, Universitas Brawijaya, Indonesia \\ ${ }^{2}$ Center for Scientific Publication, Universitas Negeri Malang, Indonesia \\ ${ }^{3}$ Tun Fatimah Form Six College, Malaysia College Sabah, Malaysia \\ ${ }^{*}$ Corresponding author. Email: esti@ub.ac.id
}

\begin{abstract}
The construct of reading and critical thinking has been extensively researched in educational contexts and argued to correlate each other. However, there is a paucity of research that explores such a relationship with how students develop their critical thinking skills. This study aims to evaluate the relationship between reading comprehension and critical thinking in an Indonesian EFL context and how critical thinking skills are developed by university students. To achieve these objectives, both quantitative and qualitative approaches were employed. The participants involved in the study 71 undergraduate university students in one of the universities in Indonesia. They were required to complete reading comprehension test and Watson-Glaser's Critical Thinking Appraisal (WGCTA), followed by semi-structured online interviews. The study reveals that reading and critical thinking are not highly correlated. Students demonstrate various ways in developing their critical thinking skills. Pedagogical implications as a bridge to literacy-based teaching are proposed.
\end{abstract}

Keywords: Critical thinking, Literacy practice, Reading, University student.

\section{INTRODUCTION}

The ability to comprehend and understand information in the texts plays an essential role in student learning. Students should be able to develop mental representation of the text being read. Reading involves the process of word identification, syntactic parsing, and discourse comprehension [14]. Besides, students are also encouraged to master critical thinking, abilities to evaluate the arguments either in the spoken or written type of information. Both reading and critical thinking are argued to correlate each other. In relation to this notion, critical thinking was evident to have a significant correlation with English proficiency [18].

In line with the extensive discussion on the theoretical perspectives of critical thinking, [5] defines critical thinking as convergent thinking as opposed to creative thinking as divergent thinking. Meanwhile, [11] defines critical thinking as "the development and evaluation of argument" (p. 259). This suggests that critical thinking is not only about active process in constructing arguments but also in evaluating them. Critical thinking has attracted many scholars in foreign language teaching, and it is considered as one of most important skills to master in the $21^{\text {st }}$ century in the existence of information explosion. The ability to collect, evaluate, and use information effectively is essential nowadays.

Furthermore, critical thinking has some characteristics covering questioning, gathering information, intellectual autonomy, and intellectual perseverance [26], [38]. In this respect, critical thinking requires patience in developing critical thinking skills as it takes times to form questions and think deeply about certain issue, and some students are easily bored [25]. On the other words, if the materials are too challenging and time consuming, students are not interested to get engaged in such materials [4]. In this digital era with many tasks to do, there is a likely that the ability to complete more tasks in a shorter amount of time is valued more than spending in a longer time for a better result. It is a challenge in its own to develop critical thinking skills. In addition to a set of skills, critical thinking also carries disposition. For instance, [27] posits that critical thinking demands open-mindedness to understand the different points of view.

Studies in field of reading and its relation to critical thinking has attracted many researchers in 
cognitive psychology. Reading comprehension is conceptualized and modelled in relation to related concepts, such as critical thinking, inference-making, prior-knowledge and metacognitive skills [22], [25], [37]. [1] posits the relation between reading and critical thinking in a way that reading involves the meaning constructed as a result of interplay between reader's critical thinking, prior knowledge, and inference-making.

This study aims to examine the degree to which reading and critical thinking correspond each other and how critical thinking is developed by university Indonesian learners.

\subsection{Theoretical frameworks}

\section{Reading and critical thinking skills}

Reading has long been argued to be associated with critical thinking in the literature. For instance, [24] posit that reading is thinking, and that reading is reasoning [28]. [14] contends that reading does not only pick up information at the word-by-word level, but it is a selective process or an active process of comprehending. This argument is related to the schema theory (assimilation and accommodation as key factors for the growth of schemata) that critical thinking is one of the ways to enhance reading comprehension concept [24]. Schema theory can explain the link between students' individual background, knowledge of the world, and critical thinking [3], [35]. In more details, schemata functions in thinking and in information comprehension can be seen from several aspects: (a) new knowledge is gained by assimilating new information into existing structure (prior knowledge), (b) schemata helps allocate the attention to old and new materials, (c) it allows for inferential elaboration of incoming information and previous experience, (d) schemata can allow information recall from memory, (e) schemata facilitate the thinking skills of summarizing and analyzing, and (f) it allows inferential construction from missing information.

The role of schemata gets more supports from [20] stating that "Schema theory posits that there is no absolute meaning on the page to be interpreted the same by all-that is, there is no "correct" comprehension. The goal of reading extended text is to arrive at a coherent representation of the text. This goal is achieved by readers' weighing and comparing data from their schemata, the text, and the context in which the act occurs".
In addition, the relation between reading and critical thinking can also be seen from the perspective that reading sometimes involves inferential and reasoning skills to establish meaningful meaning of the information (coherent mental representation). Drawing inferences depend heavily on students' schemata [1]. Thus, schema theory can be powerful rationale in building an interactive model for how reading and critical thinking is connected each other.

Furthermore, the combination of reading ability and critical thinking ability has sometimes been constructed as critical reading, requiring students to get have a deep and active engagement for the texts being read. This study proposes the conceptual framework that critical thinking and reading are interchangeably supporting each other to construct the meaning in the text, and this results in the notion of critical reading.

\section{Critical Reading}

Critical reading refers to "an approach where the reader uses higher-order cognitive skills such as the ability to analyze, synthesize, solve problems, and thinks meta-cognitively in order to negotiate meanings with the author and to construct new meaning from the text" [15]. During critical reading, students should be in conversation with the text by asking questions, making prediction, and connecting what is in the text with their previous knowledge [6]. Exploring faculty perceptions, [16] found that students' reading skills are crucial for academic success. However, the study reveals only $45 \%$ of high school students achieve the college readiness benchmark for reading [3]. Many students fall short of mastering critical reading skills or in general information literacy skills including the ability to find, evaluate, organize, use, and communicate information in all its various formats.

One of the alternatives to encourage critical reading is providing an environment which encourage strategic reading [7]. In addition, training for critical reading for teachers can also be conducted [31]. In addition, they posit several critical thinking skills from simple to complex critical reading processes, such as previewing, reviewing, and summarizing, elaborating, synthesizing, and applying. In this regard, teaching critical reading should consider the progressive nature of reading skills, particularly the connection between reading development and the hierarchical framework of Bloom's Taxonomy containing the transition from simpler to more complex skills [19], [32]. 
Previous research by [31] examined perceptions from faculty at Eastern Kentucky University $(\mathrm{n}=128)$ about 35 critical reading behaviours that they found useful in developing critical reading revealing five most useful reading skills: skimming, reviewing, synthesizing, questioning, and applying. Previously, [23] examined the students' synthesis ability and found that the participating students are in need of guidance in doing synthesis of argument in the text. This study recommends for the need of explicit instruction to master critical reading skills, such as synthesis.

\section{Cultivating critical thinking skills}

Critical thinking skills are the attribute needed by students particularly in a higher education context, since graduates with deficiency in these skills are categorized as unprepared for the workforce situation [13]. [17] considers critical thinking as a survival skill to make students go through their life. In an increasingly competitive job market nowadays, students or graduate should be able to examine the problem comprehensively to find possible solutions from different perspectives. In this regard, developing students' intellectual capabilities find its place and urgency. [9] posits the need of critical thinking in language learning and classroom teaching.

Several decades ago, [10] posits that the capacity to effectively and creatively use the knowledge including facts, codes, formulae, and rules which are all easily accessible in the digital world. Even though the technology of information brings much information, the ability to organize information and use deep reasoning to solve problem is essential to master by students. It shows a call for action for educators to equip students with sufficient problemsolving and reasoning skills. Educational institution may create an active and engaged learning environment which encourage and facilitate the development of critical thinking skills. Active learning through pair or group discussion and interaction [4].

\section{METHODS}

The present study employed both quantitative and qualitative approaches. The participants involved were seventy-one undergraduate university students enrolled in an English department in one of the public universities in Indonesia. They voluntarily participated in the study after they were informed with a consent form. The instruments used were reading test adopted from Test of English as a Foreign Language Practice Test [8], containing 50 items with five passages and Watson-Glaser's Critical Thinking Appraisal (WGCTA) [34] as a critical thinking test containing 86 points covering the critical thinking dimensions, such as argument evaluation, assumptions, deductions, inferences, interpreting information. Participants completed the tests via Google Forms, followed by open-ended items about how they develop their critical thinking skills. To check students' performance, performance category scale from [9] was adopted with the following criteria: 81 - 100 (Excellent), 61-80 (Very Good), 31-60 (Average), and 00-30 (Poor). The data were analyzed using SPSS. 21 software to calculate the correlation between reading comprehension and critical thinking skills. Open-ended responses were coded to find the theme as in relation to students' effort in developing their critical thinking skills.

\section{RESULTS AND DISCUSSIONS}

\subsection{RESULTS}

This section examines the relationship between reading comprehension and critical thinking skills and explore the ways students develop their critical thinking skills.

\section{Reading comprehension and critical thinking skills}

Reading comprehension was measured by a reading test adapted from TOEFL test, and the critical thinking was measured by Watson-Glaser's Critical Thinking Appraisal (WGCTA). The reliability of the accuracy scores on reading comprehension was .76 Cronbach Alpha and for the critical thinking was .72 overall. The reliability is above the minimum acceptable value of reliability of coefficient [12]. The data were within the ranges of normal kurtosis and skewness as the values that were not greater than 1.96 or 2.58 [12].

Interestingly, the mean accuracy for reading comprehension is $\mathrm{M}=53(S D=12.6)$ and for critical thinking is $\mathrm{M}=55(S D=8.8)$. It demonstrates that students' reading comprehension falls below $56 \%$ percent for both measurements, suggesting that they have average reading comprehension and critical thinking. The analysis showcases that on average students' critical thinking skills are still around 50\% or can answer questions correctly at half. This means that the students' critical thinking skills still need to be improved continuously, so that they will become 
graduates who are very informative and critical in absorbing information in the current era of rapid digital information technology.

In answering the first question of the study, the Pearson's product moment correlation analysis was computed. The study revealed that there was low non-significant correlation between critical thinking and reading performance at $r=.082, p=>05$. This study confirms previous study by [9] who found the correlation of $r=.089$ between reading test and critical thinking test, albeit the significant correlation was also observed.

Students' attitudes in developing critical thinking skills

To look into a more detail and get an overview of the strategy for developing students' critical thinking skills, we recruited five students who had scores above 80, and 5 students who had the lowest scores in the critical thinking test. It is important to see if there are significant differences in their perception and development of critical thinking.

Our online semi-structured interview reveals that students who have high critical thinking skills enacted multiple critical thinking strategies. Students who have a score of 100 or can answer critical thinking questions on all items shared that:

"- Do not accept information that is not yet clear. Don't rush to conclusions. Trying to think outside the box. Trying to ask questions with the words "How" and "Why". Dare to convey the assumptions you want to ask" (IB, 2021)

"Of course, it is not to take the information for granted, but it is better to look for facts related to the information by analyzing basic questions, discussing with other people, and of course reading a lot of books". (Peb, 2021)

In general, students with high critical thinking skills demonstrated that the strategies they used are questioning skills on the information received, skills in distinguishing facts or opinions from information obtained, skills in verifying and validating the truth of information, increasing search for information through one of them reading books, and the last one is reading books. discussion strategies with others.
On the other side, the strategies for developing thinking skills applied by students with the lowest scores in critical thinking (correctly responding 33\% of 86 questions) include the following information.

"Read a lot, and try to examine various points of view"

"Perhaps by meeting many people and sharing about existing problems will be able to help me improve these skills"

"Always think positive and creative to do better things"

"Reading books, discussing quality topics, and always searching for knowledge”

"Discussion, identifying problems, predicting risk, being able to distinguish fact from opinion."

In sum, students with low critical thinking skills demonstrates that, in general, there are some similarities in the development of critical thinking strategies, for example, the ability to distinguish facts and opinions, reading books. However, students with low critical thinking scores tend to be weak in the ability to verify and validate information. This can be reflected in the statement of the importance of positive thinking. This indicates the weakness of the ability to think verification of the information received.

\subsection{Discussions}

This study reveals that the relationship between reading comprehension and critical thinking skills is positive but with a low correlation $(r=.082)$. Low correlation was previously found in [9] study with $r=.089$. This indicates that there are some other factors affecting the relationship between reading and critical thinking. This study assumes that the low correlation between the two variables is due to floor effects in which participants show limited capacity in answering the two tests, as reflected in low scores for the two tests. This may be the problem of language in a sense that students are still struggling in comprehending the reading texts. It may be that the vocabulary in the text is too challenging for the participants in this study. It is evident that textual lexical difficulty affects the reading comprehension [29].

In addition, participants may be unfamiliar with critical thinking skills, so that certain training on developing students' critical thinking skills needs to be conducted. This corresponds to the previous study 
that recommends the need for critical thinking integration to curriculum and classroom setting [9]. In addition, it indicates a call for action for educators to equip students with sufficient problem-solving and reasoning skills. Educational institutions may create an active and engaged learning environment which encourage and facilitate the development of critical thinking skills. Active learning through pair or group discussion and interaction [4].

In an Indonesian setting, [36] also posits that the use of critical thinking pedagogical principles in EFL classroom can improve students' critical thinking skills and also L2 proficiency. Similarly, [30] recommend the need to utilize problem-based learning strategies to develop high-order thinking skills. In addition, [38] also posits the need for critical thinking to be incorporated in classroom as it is one of the contributing factors in the success in the $21^{\text {st }}$ century. Education authority and teacher may need to examine the mapping of the taxonomy of critical thinking posited by [21].

In addition, in online digital educational environment nowadays, [33] reveal that learning styles are correlated with the level of critical thinking skills, and that critical thinking should be integrated into online learning curriculum and online lesson plan. They further declare that "the main critical thinking skills that university students master under the guidance of teachers are inference, causal reasoning, analysis and synthesis of information, evaluation and interpretation of data". Such skills will assist students to navigate the global information space and find an optimal solution quickly for uncertainty and in unexpected situation.

\section{CONCLUSION}

The study demonstrates the evident that students at tertiary education in Indonesia are still unable comprehend the text thoroughly, evaluate information objectively, develop independent decisions and find the best solutions. As a result, they need to be explicitly trained to learn and familiarize themselves with critical thinking and critical reading. Students' perception about argument evaluation from any sources reflects the fact that students with high critical thinking skills have used strategies of questioning the information, verifying and validating the information, and using or communicating that information effectively. In response to this condition, teacher training or professional developments is urgent as to facilitate the students and provide them with the best teaching technique in developing students' critical thinking and importantly reading comprehension. Such a pedagogical implication calls for action from policy makers and education authority as well as teachers to enhance and hone critical thinking and reading abilities, so that future generation is ready for global labour market competition in the $21^{\text {st }}$ century. Findings from this study is also applicable to be a catalyst for literacybased teaching in educational contexts. In particular, the need for nurturing reading habit as a literacy tool among students is of paramount importance.

\section{CONTRIBUTIONS}

All authors conceived and designed this study. All authors contributed to the process of revising the manuscript, and at the end all author have approved the final version of this manuscript.

\section{REFERENCES}

[1] A. S. Aloqaili. The relationship between reading comprehension and critical thinking: A theoretical study. Journal of King Saud University-Languages and Translation, 2012, pp. 35-41.

[2] American College Testing (ACT). (2018). https://www.act.org/

[3] R. C. Anderson. Role of the reader's schema in comprehension, learning, and memory. In Theoretical Models and Processes of Literacy, 2018, pp. 136-145.

[4] R. Arum., \& J. Roksa. Academically adrift: Limited learning on college campuses. University of Chicago Press, 2011.

[5] B. K. Beyer. Practical strategies for the teaching of thinking. Allyn and Bacon, Longwood Division, 7 Wells Avenue, Newton, MA 02159, 1987.

[6] L. Bosley. "I don't teach reading": critical reading instruction in composition courses. Literacy Research and Instruction, 2008, pp. 285-308.

[7] L. M. Brevik. Explicit reading strategy instruction or daily use of strategies? Studying the teaching of reading comprehension through naturalistic classroom observation in English L2. Reading and writing, 2019, pp. 2281-2310. 
[8] E. Davy., \& K. Davy. Reading and Vocabulary Workbook for the TOEFL Exam. Peterson's, 2002.

[9] M. Din. Evaluating university students' critical thinking ability as reflected in their critical reading skill: A study at bachelor level in Pakistan. Thinking Skills and Creativity, 2020, pp. 100627.

[10] L. Elder. Why critical thinking is essential to the community college mission and why it will be difficult to achieve. Retrieved December, 2000, pp. 2015.

[11] P. A. Facione. Toward a theory of critical thinking. Liberal Education, 1984, pp. 253-61.

[12] A. Field. Discovering statistics using SPSS. Sage publications, 2009.

[13] K. L. Flores., G. S. Matkin., M. E. Burbach., C. E. Quinn., \& H. Harding. Deficient critical thinking skills among college graduates: Implications for leadership. Educational Philosophy and Theory, 2012, pp. 212-230.

[14] W. Grabe. Reading in a second language: Moving from theory to practice. Ernst Klett Sprachen, 2009.

[15] D. Hermida. The importance of teaching academic reading skills in first-year university courses. Available at SSRN 1419247, 2009.

[16] P. J. Howard., M. Gorzycki., G. Desa., \& D. D. Allen. Academic reading: Comparing students' and faculty perceptions of its value, practice, and pedagogy. Journal of College Reading and Learning,2018, pp. 189-209.

[17] J. Johanson. Cultivating critical thinking: An interview with Stephen Brookfield. Journal of Developmental Education, 2010, pp. 26.

[18] M. Keihaniyan. Critical thinking and language proficiency. International Journal of Language Learning and Applied Linguistics World (IJLLALW), 2013, pp. 24-32.

[19] D. R. Krathwohl. A revision of Bloom's taxonomy: An overview. Theory into practice, 2002, pp. 212-218.
[20] J. Lewis. Redefining critical reading for college critical thinking courses. Journal of Reading, 1991, pp. 420-423.

[21] X. Li., \& J. Liu. Mapping the Taxonomy of Critical Thinking Ability in EFL. Thinking Skills and Creativity, 2021, pp. 100880.

[22] B. Limbach., \& W. Waugh. Developing Higher Level Thinking. Journal of instructional pedagogies, 2010.

[23] M. Mateos., G. Rijlaarsdam., E. Martín., I. Cuevas., H. Van den Bergh., \& M. Solari. Learning paths in synthesis writing: Which learning path contributes most to which learning outcome?. Instructional Science, 2020.

[24] S. Norris., \& L. Phillips. Explanations of reading comprehension: Schema theory and critical thinking theory. Teachers College Record, 1987, pp. 281-306.

[25] C. Klassen. Learning to Think Things Through: A Guide to Critical Thinking Across the Curriculum-By Gerald M. Nosich, 2008.

[26] L. Elder., \& R. Paul. Critical thinking: Learn the tools the best thinkers use. Foundation for Critical Thinking, 2020.

[27] R. Paul. Critical thinking: What every person needs to survive in a changing world. Nassp Bulletin, 1991, pp. 120-122.

[28] V. R. Ruggiero. The Art of Thinking: A Guide to Critical and Creative Thought Harper \& Row. New York,1984.

[29] Sahiruddin. The Role of Textual Lexical Difficulty in L2 Reading Outcomes in an Indonesian EFL Tertiary Setting. The Journal of AsiaTEFL, 2021, pp. 693-700.

[30] E. Suprapto. The Application of Problem-Based Learning Strategy to Increase High Order Thinking Skills of Senior Vocational School Students. International Education Studies, 2017, pp. 123-129.

[31] A. Sutherland., \& S. Incera. Critical Reading: What Do Faculty Think Students Should Do?. Journal of College Reading and Learning, 2021, pp. 1-24. 
[32] K. Urgo., J. Arguello., \& R. Capra. Anderson and krathwohl's two-dimensional taxonomy applied to task creation and learning assessment. In Proceedings of the 2019 ACM SIGIR International Conference on Theory of Information Retrieval, 2019, pp. 117-124.

[33] L. Varenina., E. Vecherinina., E. Shchedrina., I. Valiev., \& A. Islamov. Developing critical thinking skills in a digital educational environment. Thinking Skills and Creativity, 2021, pp. 100906.

[34] G. Watson., \& E. Glaser. Watson-Glaser critical thinking appraisal, UK edition: practice test. Psychological Corporation, 2002.

[35] Y. H. Liu. Application of schema theory in teaching college English reading. Canadian Social Science, 2010, pp. 59-65.

[36] S. W. Yulianto. Critical pedagogy principles in teaching EFL reading. English Review: Journal of English Education, 2015, pp. 25-38.

[37] M. N. M. Zabit. Problem-based learning on students critical thinking skills in teaching business education in Malaysia: A literature review. American Journal of Business Education (AJBE), 2010, pp. 19-32.

[38] S. ŽivkoviL. A model of critical thinking as an important attribute for success in the $21 \mathrm{st}$ century. Procedia-social and behavioral sciences, 2016 pp.102-108. 